\title{
O Oportunismo Pré-eleitoral em nível das Despesas Públicas compensa na busca pela Reeleição nos Municípios Catarinenses no Século XXI?
}

\author{
Does Opportunism at the level of Public Expenditure Compensates in Search of Re- \\ election in Santa Catarina's Municipalities in the 21st Century?
}

\author{
Jonatan Lautenschlage \\ jlauten@eeg.uminho.pt \\ Universidade Federal de Santa Catarina (UFSC)
}

\begin{abstract}
Resumo: Da construção de estradas a aumentos dos salários dos funcionários públicos, passando por reduções nos impostos no período que antecede as eleições, as manipulações orçamentais em anos eleitorais são um fenômeno observado em diversas nações, estados e municípios em todo o mundo. Muitos políticos acreditam que, ao aumentarem as despesas no ano das eleições e durante o mandato, conseguirão aumentar as suas chances de obter um novo mandato. Mas será que isso realmente ocorre em Santa Catarina? E será que em todos os municípios catarinenses esse fenômeno é igual? Ao estudar as eleições municipais catarinenses entre 2005 e 2016, contatou-se que os eleitores de Santa Catarina premiam o comportamento oportunista de seus prefeitos, tanto nas despesas públicas, como nos investimentos. Constatou-se, também, que o oportunismo compensa nos municípios com maiores níveis de IDHM.
\end{abstract}

Palavras-Chave: Reeleição; Política fiscal; Políticos; Municípios; Santa Catarina

\begin{abstract}
From road construction to increases in public workers' salaries, through tax cuts before elections, budget manipulations in election years are a phenomenon observed in many nations, states, and municipalities around the world. Many politicians believe that by raising spending in the election year and during the term, they will increase their chances of re-election. But does this really happen in Santa Catarina? And is it that in all the municipalities of Santa Catarina this phenomenon is the same? When studying the municipal elections in Santa Catarina between 2005 and 2016, it was contacted that the voters of Santa Catarina reward the opportunistic behavior of their mayors, both in public spending and investments. It was also observed that opportunism compensates only in municipalities with higher levels of MHDI.
\end{abstract}

Keywords: Reelection; Fiscal Policy; Politicians; Municipalities; Santa Catarina 


\section{INTRODUÇÃO}

No Brasil, até a aprovação da Emenda à Constituição nº16 de 1997, que instituiu a possibilidade de reeleição, os chefes dos poderes executivos eram impedidos de concorrerem a um segundo mandato consecutivo. A partir das eleições gerais de 1998, os governadores e o presidente da República puderam buscar a reeleição, sendo a eleição local de 2000 a primeira a permitir que os prefeitos se candidatassem a mais quatro anos de governo.

Com a emergência da instituição da reeleição, surgiu, mais claramente, a possibilidade de os incumbentes fazerem uso da política fiscal, com objetivos oportunistas. Rogoff e Sibert (1988) argumentam que os governantes elevam os níveis de despesa e/ou reduzem os tributos logo antes das eleições. Ao agirem assim, sinalizam maior competência na condução da política fiscal aos seus eleitores e esperam que sejam recompensados por isso nas urnas. Rogoff (1990) foi adiante e adicionou a possibilidade de alteração, não no nível da despesa pública total, mas, sim, na sua composição.

A legislação eleitoral brasileira permite que os candidatos a cargos eletivos tenham exposição gratuita nas estações de televisão e rádio privadas e públicas ${ }^{1}$. Faz-se isso para diminuir a desigualdade na exposição dos candidatos. Geralmente, nesses programas, há exposição, por parte dos candidatos e especialmente dos incumbentes, de obras públicas e investimentos realizados durante os seus governos. Muitos políticos se utilizam dessa estratégia para mostrar as suas realizações, também para superar problemas de rejeição por parte do eleitorado, ou então somente para chamar a atenção dos cidadãos.

O exemplo mais midiático é o "roubo, mas faço", muitas vezes aludido pelo exgovernador do Estado de São Paulo e ex-prefeito de São Paulo Ademar de Barros ${ }^{2}$. Entretanto, esse mantra geralmente é relacionado ao também ex-governante paulista Paulo Maluf. Independentemente do seu criador e/ou disseminador, o ponto fulcral dessa frase é a suposta predisposição aos eleitores brasileiros premiarem com a reeleição os incumbentes que mais realizam despesas públicas, em especial os investimentos ${ }^{3}$, e que conseguem mostrar essas realizações antes das eleições.

\footnotetext{
'A exposição fica a depender da existência, ou não, de emissoras de televisão e/ou rádio na cidade. ${ }^{2} \mathrm{O}$ slogan não oficial da campanha era: "Ademar rouba, mas faz"

${ }^{3}$ Rogoff (1990) argumentava que as despesas corretes é que deveriam ser manipuladas, e não as de capital, mas o argumento de direcionamento às despesas de maior visibilidade mantém-se, uma vez que, no caso brasileiro e catarinense, ainda há uma grande demanda, pelos cidadãos, por infraestrutura.
} 
Perante esse cenário, este trabalho propõe analisar como os eleitores catarinenses se comportaram na hora de decidir se atribuíam, ou não, um segundo mandato consecutivo ao prefeito municipal, tanto com base nos níveis de despesa despendidos, como na sua composição. Serão ainda investigados diferentes horizontes temporais da realização da despesa, permitindo-se, assim, capturar o momento e o tipo de despesa que mais influenciou na decisão dos votantes barrigas-verdes. Para atingir tal objetivo, foram analisados 241 municípios entre 2001 e 2016, período este que abrange quatro eleições locais (2004, 2008, 2012 e 2016).

Este trabalho está dividido em cinco capítulos, sendo que o primeiro contextualizou a problemática; no segundo, será revista a literatura sobre a relação entre política fiscal e probabilidade de reeleição do incumbente. No terceiro, é descrito o arcabouço institucional brasileiro e catarinense. O quarto capítulo trata da estratégia metodológica a ser utilizada no exercício empírico. No quinto, são expostos e analisados os resultados e, por fim, há a conclusões.

\section{FINANÇAS PÚBLICAS E PROBABILIDADE DE REELEIÇÃO}

$\mathrm{Na}$ literatura da Economia Política, há autores que descrevem os políticos como indivíduos oportunistas, que manipulam a economia (Nordhaus, 1979) ou as componentes fiscais (Rogoff e Sibert, 1988 e Rogoff, 1990), com o objetivo de se manterem à frente do poder. Essa prática tem sido evidenciada nos vários níveis de governo ao redor do mundo, contudo, na literatura, há um debate sobre a efetividade de tais medidas: os trabalhos de Veiga e Veiga (2007) e Aidt et al. (2011) para Portugal e de Sakurai e Menezes-Filho (2008) para o Brasil $^{4}$.

Alguns autores argumentam que, em vez de serem recompensados com a reeleição, após elevarem os gastos e/ou reduzirem os impostos, os eleitores podem punir os incumbentes

\footnotetext{
${ }^{4}$ Akhmedov e Zhuravskaya (2004), ao estudarem os governos regionais russos, evidenciaram que os eleitores premiam os governantes que mais gastam antes das eleições. Isso indica que caso o político aja oportunisticamente, nos moldes descritos por Rogoff e Sibert (1988). Klein (2010) constatou que os eleitores premiaram, no período 2000-2004, os prefeitos brasileiros que gastam mais em anos eleitorais, mas o aumento do défice não pode ser exagerado. Jones et al. (2012), que ao replicar a análise de Pelzman (1992) para os governos das províncias argentinas, obteve resultados que evidenciam que, diferentemente dos eleitores norteamericanos, os cidadãos argentinos recompensam os políticos que despendam mais. Por fim, Sjahrir et al. (2013) constataram que, nos distritos indonésios, o candidato que busca a reeleição utiliza as despesas discricionárias sob sua competência para aumentar a probabilidade de reeleição
} 
oportunistas $^{5}$. Para o poder local, o trabalho empírico de Brender (2003) para os municípios israelitas evidenciou que os eleitores penalizam nas urnas os políticos que não apresentem uma boa gestão das finanças públicas ${ }^{6}$. Arvate et al. (2010) concluíram que os eleitores brasileiros, entre 1990 e 2002, punem os prefeitos que gastam mais antes das eleições ${ }^{7}$.

Rogoff (1990) argumenta que os governantes oportunistas podem gerar alterações na composição das componentes orçamentárias antes das eleições para sinalizar aos eleitores um maior nível de competência. Ao direcionar os recursos às despesas de maior visibilidade, os incumbentes esperam obter a reeleição. Nesse sentido, o trabalho de Meneguin et al. (2005) analisou os municípios brasileiros na eleição local de 2000 e constatou que os eleitores brasileiros premiam os perfeitos que apresentam maiores níveis de dispêndio com investimentos e, por outro lado, punem os que aumentam os gastos com o custeio da administração pública. Veiga e Veiga (2007) estudaram o caso do poder local português e constataram que maiores níveis de gastos com investimento nos anos eleitorais elevam as chances de o prefeito ser reeleito.

Drazen e Eslava (2010) analisaram os municípios colombianos e evidenciaram que os eleitores penalizam os políticos que geram grandes défices antes das eleições, mas recompensam os que aumentam os investimentos. Na mesma direção, Cavalcante (2016) analisou o impacto dos gastos sociais e dos investimentos na probabilidade de reeleição nos municípios brasileiros e constatou que os gastos com investimentos aumentam as chances de o incumbente obter mais um mandato governativo ${ }^{8}$.

\footnotetext{
${ }^{5}$ Pelzman (1992) foi o pioneiro nessa análise, sendo que o seu trabalho constatou que o aumento das despesas públicas não incrementa as chances de reeleição para o cargo de presidente dos Estados Unidos, nem para governador de estado. Isso indica que, caso o incumbente eleve os gastos, não será recompensado nas urnas, e sim penalizado.

${ }^{6}$ Brender e Drazen (2008) investigaram a relação entre os défices e a possibilidade de obter a reeleição, em nível das nações, e constataram que aumentos no défice antes das eleições não aumentam as chances de o político obter a reeleição, sendo que nas democracias consolidadas os votantes penalizam os incumbentes que despendam mais do que arrecadam. Veiga (2013) analisou 15 nações pertencentes à União Europeia e constatou que, após a entrada em vigor do Tratado de Maastricht, os eleitores europeus se tornaram mais conservadores no que concerne aos défices orçamentários, nomeadamente nos países sob intervenção de programas de auxílio econômico-financeiro.

${ }^{7}$ Arvate et al. (2009) analisou os estados brasileiros na eleição de 2002 e evidenciaram que os eleitores, em geral, não premiam défices, contudo, quando eles controlam para o nível de estudo da população, constataram que os cidadãos recompensam com a reeleição os partidos que apresentam superavit. Enkelmann e Leibrecht (2013), por sua vez, ao analisarem 32 nações entre 1990 e 2010 e evidenciaram que o oportunismo, pelo lado da despesa, não aumenta as chances de reeleição.

${ }^{8}$ Sedmihradska et al. (2011) evidenciaram que aumentos nas despesas de capital nos governos locais da República Checa não elevam as probabilidades de reeleição.
} 
Outro ponto importante é o horizonte temporal que o eleitor leva em consideração na hora de fazer a sua escolha de voto. Alguns cidadãos podem analisar a dinâmica dos níveis de despesa e receita pública somente no ano eleitoral. Outros já investigam a trajetória durante o mandato como um todo. Isso é relevante porque, caso o governante queira manipular a política fiscal, nos moldes de Rogoff e Sibert (1988) e Rogoff (1990), ele poderá não ter êxito, uma vez que os eleitores podem analisar os níveis de receitas e despesas públicas durante todo o mandato, e não apenas no ano eleitoral.

$\mathrm{Na}$ seara empírica, Sakurai e Menezes-Filho (2008), ao analisarem os municípios brasileiros entre 1988 e 2003, evidenciaram que os prefeitos e/ou o partido no poder que despendem mais durante o mandato são recompensados com mais quatro anos de governo. Cioffi et al. (2012) e Alesina et al. (2015) evidenciaram que os políticos locais italianos são recompensados com a reeleição, caso despendam mais durante o mandato governativo, enquanto, Chortareas et al. (2016) constataram que os aumentos nas despesas públicas municipais gregas, tanto durante o mandato como durante o período pré-eleitoral, são recompensados pelos eleitores.

\section{ARCABOUÇO INSTITUCIONAL}

Santa Catarina é um Estado localizado na Região Sul do Brasil, cujos 295 municípios são de pequeno e médio portes. A maior cidade é Joinville, com pouco mais de meio milhão de habitantes. As menores têm cerca de um milhar de indivíduos. Há também localidades com toda a população a residir na zona urbana, e outras onde a população vive majoritariamente em áreas rurais. Essa característica reflete também a composição da economia. Em certas regiões do estado, o setor primário é preponderante; em outras, é o setor secundário; e nas demais, é o setor terciário o mais importante para a economia.

Como os municípios catarinenses fazem parte dos 5570 municípios do Brasil, eles são regidos pelas mesmas leis eleitorais. O sistema eleitoral brasileiro, de acordo com a Constituição Federal Brasileira de 1988 e o Código Eleitoral (Lei n 4.737/1965 e posteriores) tem uma rigidez no que concerne às datas; por isso, pois, todas as votações ocorrem no 
primeiro domingo do mês de outubro ${ }^{9}$, sendo que as eleições locais e gerais são intercaladas, com um intervalo de dois anos entre elas. Os mandatos governativos do Poder Executivo iniciam ao primeiro dia do mês de janeiro do ano posterior às eleições e têm duração de quatro anos, renováveis por mais quatro. Os vereadores também exercem o mandato de quatro anos, mas não há limitações quando ao número de mandados consecutivos.

Outra característica marcante do sistema político-eleitoral brasileiro é a elevada troca de partidos por parte dos políticos. Segundo Mainwaring (1999), o sistema partidário brasileiro tem como característica a frouxidão no que concerne à fidelidade ao partido. Então, não é incomum que um prefeito deixe o seu partido durante o mandato e concorra à reeleição em outa agremiação política. ${ }^{10}$

No que concerne às finanças públicas, o Brasil conta com a Lei de Responsabilidade Fiscal $^{11}$ (LRF), que versa sobre a condução das contas públicas, tanto ao longo do mandato como durante o ano eleitoral. Pelo lado da despesa, essa norma jurídica foca nas despesas com pessoal, às quais impõe limites máximos consoantes à esfera de governo. Meses antes do dia da eleição, os chefes do Poder Executivo são impedidos de contratarem e/ou demitirem funcionários. Também é vetado o empenho de despesas sem a correspondente fonte de recursos explicitada, para evitar, assim, que o governante deixe uma herança de dívidas ao seu sucessor.

\section{DESCRIÇÃO DA BASE DE DADOS E DA ESTRATÉGIA ECONOMÉTRICA}

A presente seção descreve a estratégia econométrica elaborada para atingir os objetivos deste trabalho. Inicia-se com a definição da variável dependente e do modelo econométrico e, depois, migra-se para a descrição das variáveis explicativas: primeiramente as de cunho fiscal e, por fim, as variáveis que representam as características socioeconômicas de cada município.

\footnotetext{
${ }^{9}$ Nos municípios com número de eleitores superior a 200 mil, caso um dos candidatos não atinja $50 \%$ dos votos válidos (excluem-se votos brancos e nulos) mais 1, é necessária a realização de uma segunda volta com os dois candidatos que angariaram mais votos, sendo que esta ocorre em outro domingo, também do mês de outubro, respeitando o período mínimo legal de 10 dias.

10 Sakurai e Menezes-Filho (2008) e Arvate et al. (2010) estudaram a relação das despesas com a manutenção do partido no poder, contudo, esse procedimento pode não ser acertado, dada a baixa fidelidade ao partido. Sendo assim, neste trabalho escolheu-se investigar o impacto da política fiscal somente sobre a reeleição do prefeito, deixando de lado a questão da permanência do partido à frente da Prefeitura.

${ }^{11}$ Lei Complementar $n^{\circ} 101$, de 4 de maio de 2000
} 


\section{Variável dependente e modelo econométrico}

Como este trabalho tem o objetivo de analisar o impacto das despesas públicas locais sobre a probabilidade de o prefeito ser reeleito em Santa Catarina, utiliza-se como variável dependente a variável, que assume o valor um quando o prefeito que concorreu à reeleição consegue atingir o seu objetivo e zero, caso não seja reeleito. Isso significa que apenas os chefes do Poder Executivo local que se recandidataram são considerados na amostra. A base de dados utilizada para atingir os objetivos deste trabalho é constituída por $241^{12}$ municípios catarinenses, e o horizonte temporal vai do ano de 2005 ao ano de 2016.

Segundo Greene (2012), Verbeek (2008) e Davidson e MacKinnon (1999), quando se está diante de uma situação em que a variável dependente ( assume o valor zero ou o valor um, estamos perante um modelo de escolha binária. Considerando a probabilidade de haver sucesso na busca por um novo mandato ( ) e que está condicionada a um vetor de variáveis exógenas e predeterminadas contidas no vetor, temos que a relação entre e

pode ser definida como:

$$
E\left(y_{i t} \mid X_{i t}\right)=P_{i t}=F\left(X_{i t} \beta\right)(i)
$$

Em que $F(x)$ é a função de distribuição e $F(-\infty)=0, F(\infty)=1$ e $f(x)=\frac{\partial F}{\partial x}>0$.

Ainda de acordo com Greene (2012), Verbeek (2008) e Davidson e MacKinnon (1999), para estimar esse modelo não linear, pode-se fazer uso do método probit, que assume que a função distribuição é definida segundo a distribuição normal $F\left(X_{t} \beta\right)=\Phi\left(X_{t} \beta\right)$. Neste trabalho, são utilizados dados tanto em painel como seccionais. No que concerne às estimações com dados em painel por meio do método probit, há a possibilidade de utilizar o método com efeitos fixos ou com efeitos aleatórios. Pela característica do exercício econométrico aplicado neste trabalho, o método por efeitos fixos acaba por eliminar muitas observações, uma vez que há municípios nos quais, em todas as eleições, o prefeito se recandidatou e foi reeleito, ou nunca foi reeleito, o que leva à exclusão destes devido à colinearidade com o efeito fixo. Posto isso, para evitar a elevada perda de dados, optou-se por utilizar o modelo de efeitos aleatórios, com

\footnotetext{
12 Foram retirados os municípios criados durante o período analisado e as localidades nas quais ocorreram eleições suplementares, ou seja, houve realização de eleições na localidade no meio do mandato. Geralmente, essas votações são convocadas quando o prefeito tem seu mandato cassado, em caso de falecimento ou de impossibilidade de o prefeito de se manter no poder. Assim, quem assume é o vice-prefeito, eleito conjuntamente com o prefeito.
} 
erros-padrão robustos e uma dummy para cada eleição, para ser possível capturar as especificidades de cada pleito municipal ${ }^{13}$.

Por se tratar de um modelo não linear, os coeficientes estimados segundo o método probit não representam diretamente o impacto de uma variável sobre a probabilidade de $\mathrm{o}$ evento acontecer. No caso deste trabalho, o prefeito, candidato à reeleição, ser reeleito.

Para facilitar a análise, utiliza-se o efeito marginal de cada variável. O efeito marginal do modelo ( $i$ ) é assim definido:

$$
\frac{\partial E\left(y_{i t} \vee X_{i t}\right)}{\partial x_{i t}}=f\left(X_{i t} \beta\right) \beta_{i t}(i)
$$

o que indica que esse efeito marginal depende do vetor $X_{i t}$ por via $f\left(X_{i t} \beta\right)$, o que indica que não é constante, como ocorre nos modelos lineares. Por se tratar de um modelo não linear, o teste apropriado para a significância global do modelo de escolha binária é o teste da razão de máxima verossimilhança (LR), obtido ao se calcular duas vezes a diferença entre os dois maiores valores máximos resultantes da função de log-verossimilhança ${ }^{14}$, entre o modelo restrito e o não restrito. A hipótese nula é a de que, simultaneamente, todos os coeficientes são nulos e seguem a distribuição chi-quadrado (Davidson e MacKinnon, p. 453, 1999).

\section{Variáveis explicativas}

O modelo $i$ objetiva investigar como determinadas variáveis influenciaram, ou não, a probabilidade de reeleição dos prefeitos catarinenses. Nessas subseção, são explicitadas e explicadas quais as variáveis estão contidas no vetor. Para facilitar, as variáveis estão divididas em dois grupos:

- Despesas públicas municipais; e

- Variáveis de controle da realidade socioeconômica do município.

\footnotetext{
${ }^{13}$ Para evitar colinearidade das variáveis referentes às eleições, escolheu-se a variável referente às eleições de 2008 como base, ou seja, ela foi retirada das estimações, sendo mantidas somente as vaiáveis dummy para as eleições de 2012 e 2016.

${ }^{14} l(y, \beta)=\sum_{t=1}^{n}\left(y_{i t} \log \left(F\left(X_{i t} \beta\right)\right)+\left(1-y_{i t}\right) \log \left(1-F\left(X_{i t} \beta\right)\right)\right)$
} 


\section{Despesas públicas municipais}

Para ser possível analisar como as despesas públicas se relacionam com a probabilidade de reeleição dos prefeitos catarinense é preciso explicar quais serão as variáveis utilizadas, o porquê de utilizá-las e os resultados esperados. Dentre as variáveis explicativas contidas no vetor, há as despesas:

- Totais ( );

- Com pessoal ( ); e

- Investimento ( ).

Todas as variáveis fiscais estão expressas em termos per capita a preços constantes de 31 de dezembro de $2016^{15}$.

De acordo com a teoria do oportunismo eleitoral (Rogoff e Sibert, 1988), é no ano eleitoral que ocorrem as manipulações nas despesas públicas, objetivando a elevação na probabilidade do incumbente manter-se no poder. Esse comportamento eleitoreiro possivelmente não será capturado somente ao se analisar os níveis de despesas empenhados no ano eleitoral ( ).

Conforme proposto por Rogoff e Sibert (1988), no ano eleitoral há uma alteração nos padrões das despesas, ou seja, um aumento. Posto isso, para sugerir que o oportunismo compensa nas localidades catarinenses é necessária a utilização das despesas públicas

expressas em outros termos. O primeiro é obtido por meio do cálculo do desvio ) entre

o valor das despesas empenhadas no ano eleitoral $\left(E_{i t}\right)$, em face da média do mandato $\left(\right.$ Mandato $\left._{i t}\right)$, o que permite identificar se, ao se desviar mais, elevam-se ou não as probabilidades de reeleição. O segundo modo é calcular a variação entre os níveis da despesa no ano eleitoral com os seus valores no primeiro ano do mandato (Variação $o_{i t}$ ). Desta forma, se a análise se concentrar às despesas no final do mandato (ano eleitoral) é ou não mais vantajoso, em termos de elevação na probabilidade de reeleição.

\footnotetext{
${ }^{15}$ IGP-DI/FGV
} 
Tabela 1- Estatística descritiva das variáveis

\begin{tabular}{|lcccccc|}
\hline & & $(1)$ & $(2)$ & $(3)$ & $(4)$ & $(5)$ \\
\hline Variáveis & Fonte & N & Média & $\begin{array}{c}\text { Desvio } \\
\text { Padrão }\end{array}$ & Mínimo & Máximo \\
& & & & & \\
Reeleito & Tribunal Superior Eleitoral & 241 & 0.614 & 0.488 & 0 & 1 \\
DespesaE & Secretaria do Tesouro Nacional & 241 & 3.302 & 1.252 & 1.475 & 9.371 \\
PessoalE & Secretaria do Tesouro Nacional & 241 & 1.438 & 0.553 & 0.610 & 3.623 \\
InvestimentoE & Secretaria do Tesouro Nacional & 241 & 0.524 & 0.400 & 0.0553 & 4.848 \\
DespesaMandato & Secretaria do Tesouro Nacional & 241 & 3.051 & 1.222 & 1.243 & 7.649 \\
PessoalMandato & Secretaria do Tesouro Nacional & 241 & 1.331 & 0.524 & 0.573 & 3.466 \\
InvestimentoMandato & Secretaria do Tesouro Nacional & 241 & 0.442 & 0.306 & 0.0610 & 2.637 \\
DespesaDesvio & Secretaria do Tesouro Nacional & 241 & 0.0956 & 0.0934 & -0.161 & 0.337 \\
PessoalDesvio & Secretaria do Tesouro Nacional & 241 & 0.0855 & 0.0762 & -0.0872 & 0.418 \\
InvestimentoDesvio & Secretaria do Tesouro Nacional & 241 & 0.255 & 0.454 & -0.890 & 1.800 \\
DespesaVariacao & Secretaria do Tesouro Nacional & 241 & 6.372 & 10.76 & -22.21 & 59.12 \\
PessoalVariacao & Secretaria do Tesouro Nacional & 241 & 4.385 & 7.968 & -14.98 & 28.59 \\
InvestimentoVariacao & Secretaria do Tesouro Nacional & 241 & 51.61 & 101.2 & -90.82 & 579.0 \\
TributosE & Secretaria do Tesouro Nacional & 241 & 0.243 & 0.231 & 0.0385 & 3.064 \\
IDHM & IBGE & 241 & 0.670 & 0.0805 & 0.453 & 0.809 \\
IDHM_E & IBGE & 241 & 0.538 & 0.124 & 0.238 & 0.749 \\
IDHM_L & IBGE & 241 & 0.820 & 0.0427 & 0.719 & 0.894 \\
IDHM_R & IBGE & 241 & 0.691 & 0.0589 & 0.528 & 0.848 \\
Urbano & IBGE & 241 & 0.554 & 0.246 & 0.0996 & 1 \\
Percentagem & ThGibunal Superior Eleitoral & 239 & 0.530 & 0.108 & 0.274 & 1 \\
Esquerda & Tribunal Superior Eleitoral & 241 & 0.129 & 0.335 & 0 & 1 \\
Pres2 & Tribunal Superior Eleitoral & 239 & 0.113 & 0.317 & 0 & 1 \\
Gov2 & Tribunal Superior Eleitoral & 239 & 0.259 & 0.439 & 0 & 1 \\
Eleição2008 & & 241 & 0.506 & 0.501 & 0 & 1 \\
Eleição2012 & 241 & 0.282 & 0.451 & 0 & 1 \\
\hline Eleição2016 & & 241 & 0.212 & 0.409 & 0 & 1 \\
\hline & & & & & & \\
\hline
\end{tabular}

Rogoff (1990) propôs que o oportunismo pode ocorrer não nas despesas totais, mas sim na sua composição. Desta forma, para analisar como o eleitorado catarinense reage a essa composição, pesquisou-se, de forma análoga à análise das despesas totais, as despesas com pessoal ( $\quad$ Iit $)$ e com investimento ( $\quad$ Iit $)$. As duas variáveis também foram

expressas nos quatro horizontes temporais (ano eleitoral, média do mandato, desvio entre o valor das despesas empenhadas no ano eleitoral, em face da média do mandato e, por fim, a variação entre os níveis da despesa no ano eleitoral e seus valores no primeiro ano do mandato).

As despesas com pessoal foram escolhidas pelo fato de serem a principal componente das despesas dos municípios catarinenses. Outro ponto importante é que, em muitos municípios, nomeadamente os com menor população, o Poder Executivo local é um dos 
maiores empregadores local. Então, essa rubrica apresenta um elevado grau de conhecimento pela população. Entretanto, não se podem traçar expectativas sobre a relação causal entre as despesas com pessoal e a probabilidade de reeleição, especialmente na questão relativa ao oportunismo, uma vez que a LRF impõe limites a essa rubrica tanto durante o mandato quanto durante o ano eleitoral.

Já os investimentos são os que, tradicionalmente, são os escolhidos pelos candidatos à reeleição para serem mostrados em suas campanhas. Ou seja, geralmente os prefeitos que buscam a reeleição elencam, durante o período eleitoral, as obras realizadas e inauguradas ao longo do seu mandato. Como o Brasil e Santa Catarina são carentes de infraestruturas, esperase que essas despesas tenham uma relação positiva com a probabilidade de reeleição do prefeito, uma vez que esses investimentos tendem a gerar um benefício significativo à população do município.

\section{Variáveis explicativas: controle da realidade socioeconômica}

Ao observarem os níveis e composição da despesa pública, os eleitores apresentam comportamento diverso, sendo que as características socioeconômicas e demográficas da localidade podem ter influência no modo como os diferentes eleitores reagem à trajetória e à composição da despesa pública. Posto isso, é recorrente na literatura que sejam incluídas variáveis de controle no vetor, para que possam capturar esses efeitos.

Neste trabalho empírico, faz-se uso das seguintes variáveis de controle para a demografia e nível socioeconômico:

- indicam o valor real das receitas tributárias per capita do município $i$ arrecadado no eleitoral $t$. Essa variável funciona como uma proxy da atividade econômica, uma vez que os principais tributos municipais, o IPTU (imposto predial e territorial urbano) e o ISS (imposto sobre serviços de qualquer natureza), estão intimamente correlacionados à atividade econômica local. O resultado expectado para a relação entre os níveis de receitas tributárias e a probabilidade de reeleição do candidato não pode ser previsto. Por um lado, o fato de a população ter pago mais tributos no ano com eleições pode diminuir o apreço pelo governante local. Entretanto, maiores arrecadações no ano eleitoral podem ser oriundas de um período de aceleração econômica e, desta forma, o eleitor pode recompensar o prefeito, pelo fato de a economia estar aquecida. Outro ponto importante é que o IPTU e ITBI são impostos diretos, cuja incidência legal e econômica é a mesma, ou seja, o cidadão recolhe 
o valor do imposto diretamente, enquanto o ISS é um imposto indireto, que geralmente repercute e, portanto, a incidência econômica não é a mesma da legal.

- : representa o índice de desenvolvimento humano municipal do município catarinense $i$ no eleitoral $t$. Essa é a variável que apresenta uma função central neste trabalho, pois é ela que testará a possível existência de relação causal entre a probabilidade de reeleição e o nível de desenvolvimento, ou seja, se a população dos municípios mais desenvolvidos, em termos socioeconômicos, é menos influenciada pelo oportunismo préeleitoral. Espera-se que haja, sim, uma relação causal inversa e estatisticamente significativa. Como o IDHM é uma média geométrica de três índices (IDHM educação, IDHM renda e IDHM longevidade), é pertinente analisar a relação entre cada um deles e a probabilidade de reeleição. Posto isso, utilizam-se as variáveis , e, que representam essas subcomponentes do índice de desenvolvimento humano municipal.

- $\quad$ : percentual da população do município $i$ no eleitoral $t$ que residia na zona urbana. A relevância da distinção entre a parcela da população urbana e rural de um município tem sido justificada amplamente na literatura sobre relação da política fiscal e reeleição, em decorrência da possível assimetria de percepção dos níveis e composição da despesa pública. No caso de Santa Catarina, essa questão se torna patente devido à existência de municípios amplamente urbanizados e outros com a maioria dos seus cidadãos a residir em zonas rurais.

- $\quad$ : assume o valor um caso o prefeito seja de partidos de esquerda ${ }^{16}$ e zero caso o chefe do Poder Executivo local catarinense seja de uma agremiação política de centro ou de direita. A literatura sobre a relação das despesas públicas e probabilidade de reeleição geralmente utiliza a ideologia do incumbente como fator condicionante no momento de o eleitor escolher seu candidato. O Brasil é um país onde a questão ideológica e a fidelidade partidária são muito fluidas, como argumenta Mainwaring (1999), uma vez que os políticos mudam de partido com grande facilidade. Traçado esse cenário, é fundamental

\footnotetext{
${ }^{16}$ Essa classificação foi realizada por Zucco (2011).
} 
investigar se os catarinenses ${ }^{17}$ consideram, ou não, a ideologia do prefeito no momento de decidirem se o reelegem ou não. Para tal, faz-se uso dessa variável.

- $\quad$ Percentual $_{i t-1}$ : representa o percentual de votos obtidos na eleição anterior $(t-1)$ pelo prefeito que busca a reeleição. Quando se está a analisar a influência de variáveis na probabilidade de reeleição dos incumbentes, é fundamental que se investigue como o seu "patrimônio eleitoral" prévio impacta nas chances de permanecer no poder por mais um

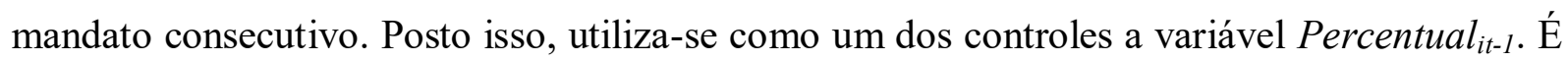
expectado que prefeitos eleitos pela primeira vez e que tenham recebidos maiores percentuais de votos válidos tendem a se sentir mais seguros no momento de buscar a reeleição, em decorrência da sua herança eleitoral. Ou seja, supõem-se que grande parte dos seus eleitores manter-se-ão fieis a ele no momento de reeleição. Por exemplo, um prefeito que tenha recebido $2 / 3$ dos votos, mesmo que ele perca $1 / 4$ dos seus eleitores, ficará ainda com uma votação perto dos $50 \%$, o que significaria a criação de um eleitorado cativo, o que, por sua vez, pode influenciar os resultados eleitorais. ${ }^{18}$

- No Brasil, as transferências intergovernamentais recebidas dos governos federal e estadual são a principal fonte de recursos da maioria dos municípios catarinenses. Essa realidade torna necessário que se controle para a relação política entre os governantes das diferentes esferas de governo. é uma variável dummy que assume o valor um caso o prefeito seja do mesmo partido que o do presidente da República e zero caso seja de outra agremiação política. assume o valor 1 caso o prefeito do município $i$ seja do mesmo partido que o do governador de estado, durante a segunda ${ }^{19}$ parte do governo. O resultado esperado é que não haja uma relação entre o alinhamento ao governador do estado e/ou ao presidente da República e a probabilidade de reeleição dos prefeitos catarinense, em

\footnotetext{
${ }^{17}$ Lautenschlage (2018), ao investigar se os prefeitos catarinenses são oportunistas, não evidenciou diferenças estatisticamente significativas entre governantes de partidos de esquerda, quando comparados aos de centro e de direita.

${ }^{18}$ De acordo com as conclusões Veiga e Veiga (2007), Aidt et al. (2011), Arvate et al. (2010) e Drazen e Eslava (2010) para os poderes locais portugueses, brasileiros e colombianos, respectivamente, a margem de vitória do político tem impacto na probabilidade de ele conseguir um segundo mandato consecutivo, ou seja, para eles, quanto maior for a quantidade de votos recebidos, mais elevada é a possibilidade de reeleição. No sentido oposto, Brender e Drazen (2008) não evidenciaram uma relação entre os votos recebidos e as chances de reeleição, quando analisaram 74 democracias.

${ }^{19}$ Essa distinção é necessária, uma vez que as eleições locais e gerais no Brasil são intercaladas, com diferença de 2 anos entre uma e outra.
} 
decorrência das especificidades das eleições municipais, que geralmente são focadas em questões locais. Contudo, é salutar à análise a inclusão dessas duas variáveis.

\section{RESULTADOS}

Neste capítulo, são expostos e analisados os resultados obtidos com a estimação pelo método Probit com Efeitos Aleatórios do modelo $i$, bem como os seus respectivos efeitos marginais, para os $241^{20}$ governos locais catarinenses, entre os anos 2005 e 2016. Todas as estimações mostraram-se globalmente significativas pelo teste de significância razão de máxima verossimilhança (LR) e os seus resultados estão expostos nas Tabelas 2 e 3.

\section{Despesas públicas e reeleição}

Antes de focar no estudo acerca de o oportunismo compensar ou não, é providencial analisar como se dá a relação entre as despesas públicas durante o ano com eleições e a sua média ao longo do mandato.

Quando se analisa a relação causal entre as despesas totais despendidas e a probabilidade de reeleição dos prefeitos catarinenses entre 2005 e 2016, observa-se, conforme indicam os resultados expostos na Coluna 1 do Painel I da Tabela 2 , que essas despesas não exercem influência sobre a probabilidade de reeleição. Esse resultado sugere que os eleitores catarinenses não recompensam os prefeitos que gastam mais nos anos com votações locais. Esse resultado está alinhado com as conclusões de Sakurai e Menezes Filho (2008), que analisaram os municípios brasileiros e evidenciaram que, entre 1988 e 2000, não houve relação entre o nível de despesa despendido nos anos eleitorais e as chances de o partido se manter no poder.

Entretanto, quando se utilizam as três componentes do IDHM separadamente (Painel II da Tabela 2), as despesas totais empenhadas no ano eleitoral, conforme sugerem $(10 \%$ de significância) os resultados expostos na Coluna 1, aumentam as chances reeleição. Para cada elevação de mil reais nas despesas, a probabilidade de reeleição se eleva, em média, 6,4 ${ }^{21}$ pontos percentuais, ceteri paribus. Como o resultado obtido para Santa Catarina tem somente $10 \%$ de significância, é prematuro afirmar que o comportamento catarinense se difere do restante do dos eleitores brasileiros, como evidenciado por Sakurai e Menezes Filho (2008).

\footnotetext{
${ }^{20}$ Só fazem parte da amostra os municípios cujos prefeitos buscaram a reeleição.

${ }^{21}$ Relação Linear-logaritmo
} 
Tabela 2 - Despesas totais e a probabilidade de reeleição

\begin{tabular}{|c|c|c|c|c|c|c|c|c|c|c|c|c|c|c|c|c|}
\hline \multirow[b]{3}{*}{ VARIÁVEIS } & \multicolumn{8}{|c|}{ Painel (I) } & \multicolumn{8}{|c|}{ Painel (II) } \\
\hline & \multicolumn{2}{|c|}{$\begin{array}{c}(1) \\
\text { Eleitoral }\end{array}$} & \multicolumn{2}{|c|}{$\begin{array}{c}(2) \\
\text { Mandato } \\
\end{array}$} & \multicolumn{2}{|c|}{$\begin{array}{c}\text { (3) } \\
\text { Desvio } \\
\end{array}$} & \multicolumn{2}{|c|}{$\begin{array}{c}(4) \\
\text { Variação }\end{array}$} & \multicolumn{2}{|c|}{$\begin{array}{c}(1) \\
\text { Eleitoral } \\
\end{array}$} & \multicolumn{2}{|c|}{$\begin{array}{c}(2) \\
\text { Mandato } \\
\end{array}$} & \multicolumn{2}{|c|}{$\begin{array}{c}\text { (3) } \\
\text { Desvio } \\
\end{array}$} & \multicolumn{2}{|c|}{$\begin{array}{c}(4) \\
\text { Variação } \\
\end{array}$} \\
\hline & Probit & $\begin{array}{c}\text { Efeito } \\
\text { Marginal }\end{array}$ & Probit & $\begin{array}{c}\text { Efeito } \\
\text { Marginal }\end{array}$ & Probit & $\begin{array}{c}\text { Efeito } \\
\text { Marginal }\end{array}$ & Probit & $\begin{array}{c}\text { Efeito } \\
\text { Marginal }\end{array}$ & Probit & $\begin{array}{c}\text { Efeito } \\
\text { Marginal }\end{array}$ & Probit & $\begin{array}{c}\text { Efeito } \\
\text { Marginal }\end{array}$ & Probit & $\begin{array}{c}\text { Efeito } \\
\text { Marginal }\end{array}$ & Probit & $\begin{array}{c}\text { Efeito } \\
\text { Marginal }\end{array}$ \\
\hline Despesa & $\begin{array}{c}0.166 \\
(1.544)\end{array}$ & $\begin{array}{c}0.057 \\
(1.591)\end{array}$ & $\begin{array}{l}0.0878 \\
(0.779)\end{array}$ & $\begin{array}{c}0.030 \\
(0.784)\end{array}$ & $\begin{array}{c}3.674 * * \\
(2.397)\end{array}$ & $\begin{array}{c}1.210 * * * \\
(2.586)\end{array}$ & $\begin{array}{l}0.0243^{* *} \\
(2.168)\end{array}$ & $\begin{array}{l}0.008 * * \\
(2.256)\end{array}$ & $\begin{array}{l}0.189^{*} \\
(1.721)\end{array}$ & $\begin{array}{l}0.064^{*} \\
(1.794)\end{array}$ & $\begin{array}{c}0.111 \\
(0.972)\end{array}$ & $\begin{array}{c}0.038 \\
(0.983)\end{array}$ & $\begin{array}{l}3.738^{* *} \\
(2.403)\end{array}$ & $\begin{array}{c}1.218 * * * \\
(2.595)\end{array}$ & $\begin{array}{c}0.0248^{* *} \\
(2.209)\end{array}$ & $\begin{array}{l}0.008^{* *} \\
(2.299)\end{array}$ \\
\hline IDHM & $\begin{array}{l}-5.203^{* *} \\
(-1.999)\end{array}$ & $\begin{array}{l}-1.780^{* *} \\
(-2.092)\end{array}$ & $\begin{array}{l}-5.097 * * \\
(-1.963)\end{array}$ & $\begin{array}{l}-1.758^{* *} \\
(-2.042)\end{array}$ & $\begin{array}{c}-4.573 \\
(-1.592)\end{array}$ & $\begin{array}{l}-1.506 \\
(-1.637)\end{array}$ & $\begin{array}{l}-4.849^{*} \\
(-1.802)\end{array}$ & $\begin{array}{l}-1.638^{*} \\
(-1.853)\end{array}$ & & & & & & & & \\
\hline IDHM_E & & & & & & & & & $\begin{array}{c}-5.250^{* *} \\
(-2.272)\end{array}$ & $\begin{array}{c}-1.773 * * \\
(-2.455)\end{array}$ & $\begin{array}{c}-5.005^{* *} \\
(-2.185)\end{array}$ & $\begin{array}{c}-1.706 * * \\
(-2.336)\end{array}$ & $\begin{array}{l}-4.355^{*} \\
(-1.801)\end{array}$ & $\begin{array}{l}-1.419^{*} \\
(-1.903)\end{array}$ & $\begin{array}{l}-4.627^{* *} \\
(-2.023)\end{array}$ & $\begin{array}{r}-1.545^{* *} \\
(-2.133)\end{array}$ \\
\hline IDHM_R & & & & & & & & & $\begin{array}{l}1.170 \\
(0.359)\end{array}$ & $\begin{array}{c}0.395 \\
(0.360)\end{array}$ & $\begin{array}{c}0.925 \\
(0.287)\end{array}$ & $\begin{array}{c}0.315 \\
(0.287)\end{array}$ & $\begin{array}{c}0.0570 \\
(0.0174)\end{array}$ & $\begin{array}{c}0.019 \\
(0.017)\end{array}$ & $\begin{array}{l}0.360 \\
(0.113)\end{array}$ & $\begin{array}{c}0.120 \\
(0.113)\end{array}$ \\
\hline IDHM_L & & & & & & & & & $\begin{array}{l}3.415 \\
(0.734)\end{array}$ & $\begin{array}{l}1.153 \\
(0.739)\end{array}$ & $\begin{array}{l}3.295 \\
(0.709)\end{array}$ & $\begin{array}{l}1.123 \\
(0.714)\end{array}$ & $\begin{array}{l}4.501 \\
(0.932)\end{array}$ & $\begin{array}{l}1.467 \\
(0.939)\end{array}$ & $\begin{array}{l}3.983 \\
(0.865)\end{array}$ & $\begin{array}{c}1.329 \\
(0.870)\end{array}$ \\
\hline Urbano & $\begin{array}{c}0.505 \\
(0.736)\end{array}$ & $\begin{array}{c}0.173 \\
(0.742)\end{array}$ & $\begin{array}{c}0.252 \\
(0.358)\end{array}$ & $\begin{array}{c}0.087 \\
(0.358)\end{array}$ & $\begin{array}{c}-0.300 \\
(-0.448)\end{array}$ & $\begin{array}{c}-0.099 \\
(-0.449)\end{array}$ & $\begin{array}{r}-0.0748 \\
(-0.122)\end{array}$ & $\begin{array}{l}-0.025 \\
(-0.122)\end{array}$ & $\begin{array}{c}0.560 \\
(0.828)\end{array}$ & $\begin{array}{c}0.189 \\
(0.834)\end{array}$ & $\begin{array}{c}0.302 \\
(0.436)\end{array}$ & $\begin{array}{c}0.103 \\
(0.437)\end{array}$ & $\begin{array}{l}-0.332 \\
(-0.507)\end{array}$ & $\begin{array}{l}-0.108 \\
(-0.510)\end{array}$ & $\begin{array}{l}-0.0983 \\
(-0.165)\end{array}$ & $\begin{array}{l}-0.033 \\
(-0.166)\end{array}$ \\
\hline Percentagem & $\begin{array}{c}1.417 \\
(1.436)\end{array}$ & $\begin{array}{c}0.485 \\
(1.461)\end{array}$ & $\begin{array}{l}1.487 \\
(1.506)\end{array}$ & $\begin{array}{c}0.513 \\
(1.536)\end{array}$ & $\begin{array}{c}1.728 \\
(1.608)\end{array}$ & $\begin{array}{l}0.569^{*} \\
(1.649)\end{array}$ & $\begin{array}{l}1.610 \\
(1.575)\end{array}$ & $\begin{array}{c}0.544 \\
(1.613)\end{array}$ & $\begin{array}{c}1.571 \\
(1.572)\end{array}$ & $\begin{array}{c}0.530 \\
(1.603)\end{array}$ & $\begin{array}{c}1.631 \\
(1.639)\end{array}$ & $\begin{array}{l}0.556^{*} \\
(1.675)\end{array}$ & $\begin{array}{l}1.878^{*} \\
(1.749)\end{array}$ & $\begin{array}{l}0.612^{*} \\
(1.793)\end{array}$ & $\begin{array}{l}1.768^{*} \\
(1.729)\end{array}$ & $\begin{array}{l}0.590^{*} \\
(1.774)\end{array}$ \\
\hline Esquerda & $\begin{array}{l}-0.809 \\
(-0.934)\end{array}$ & $\begin{array}{l}-0.277 \\
(-0.951)\end{array}$ & $\begin{array}{l}-0.805 \\
(-0.940)\end{array}$ & $\begin{array}{l}-0.278 \\
(-0.955)\end{array}$ & $\begin{array}{c}-0.862 \\
(-0.928)\end{array}$ & $\begin{array}{l}-0.284 \\
(-0.946)\end{array}$ & $\begin{array}{l}-0.810 \\
(-0.948)\end{array}$ & $\begin{array}{l}-0.274 \\
(-0.964)\end{array}$ & $\begin{array}{l}-0.821 \\
(-0.999)\end{array}$ & $\begin{array}{l}-0.277 \\
(-1.019)\end{array}$ & $\begin{array}{l}-0.818 \\
(-1.004)\end{array}$ & $\begin{array}{l}-0.279 \\
(-1.023)\end{array}$ & $\begin{array}{l}-0.859 \\
(-0.946)\end{array}$ & $\begin{array}{l}-0.280 \\
(-0.967)\end{array}$ & $\begin{array}{l}-0.816 \\
(-0.985)\end{array}$ & $\begin{array}{c}-0.272 \\
(-1.004)\end{array}$ \\
\hline Pres2 & $\begin{array}{c}0.858 \\
(0.947)\end{array}$ & $\begin{array}{c}0.294 \\
(0.962)\end{array}$ & $\begin{array}{c}0.830 \\
(0.925)\end{array}$ & $\begin{array}{l}0.286 \\
(0.938)\end{array}$ & $\begin{array}{c}0.880 \\
(0.908)\end{array}$ & $\begin{array}{c}0.290 \\
(0.924)\end{array}$ & $\begin{array}{c}0.829 \\
(0.928)\end{array}$ & $\begin{array}{c}0.280 \\
(0.943)\end{array}$ & $\begin{array}{c}0.905 \\
(1.047)\end{array}$ & $\begin{array}{l}0.305 \\
(1.067)\end{array}$ & $\begin{array}{c}0.874 \\
(1.020)\end{array}$ & $\begin{array}{c}0.298 \\
(1.037)\end{array}$ & $\begin{array}{l}0.898 \\
(0.948)\end{array}$ & $\begin{array}{c}0.293 \\
(0.968)\end{array}$ & $\begin{array}{c}0.858 \\
(0.990)\end{array}$ & $\begin{array}{c}0.287 \\
(1.008)\end{array}$ \\
\hline Gov2 & $\begin{array}{c}0.244 \\
(1.049)\end{array}$ & $\begin{array}{c}0.083 \\
(1.058)\end{array}$ & $\begin{array}{c}0.242 \\
(1.048)\end{array}$ & $\begin{array}{c}0.084 \\
(1.056)\end{array}$ & $\begin{array}{c}0.235 \\
(0.952)\end{array}$ & $\begin{array}{c}0.077 \\
(0.956)\end{array}$ & $\begin{array}{c}0.168 \\
(0.698)\end{array}$ & $\begin{array}{c}0.057 \\
(0.700)\end{array}$ & $\begin{array}{c}0.232 \\
(0.990)\end{array}$ & $\begin{array}{c}0.078 \\
(0.999)\end{array}$ & $\begin{array}{c}0.231 \\
(0.993)\end{array}$ & $\begin{array}{c}0.079 \\
(1.001)\end{array}$ & $\begin{array}{c}0.221 \\
(0.891)\end{array}$ & $\begin{array}{c}0.072 \\
(0.895)\end{array}$ & $\begin{array}{c}0.154 \\
(0.641)\end{array}$ & $\begin{array}{c}0.051 \\
(0.642)\end{array}$ \\
\hline TributosE & $\begin{array}{l}1.151^{*} \\
(1.789)\end{array}$ & $\begin{array}{l}0.394 * \\
(1.830)\end{array}$ & $\begin{array}{l}1.299 * \\
(1.944)\end{array}$ & $\begin{array}{l}0.448 * * \\
(1.996)\end{array}$ & $\begin{array}{l}1.581^{*} \\
(1.815)\end{array}$ & $\begin{array}{l}0.521^{*} \\
(1.863)\end{array}$ & $\begin{array}{l}1.535^{*} \\
(1.954)\end{array}$ & $\begin{array}{l}0.519 * * \\
(1.996)\end{array}$ & $\begin{array}{l}1.097^{*} \\
(1.908)\end{array}$ & $\begin{array}{c}0.370^{* *} \\
(1.966)\end{array}$ & $\begin{array}{l}1.246 * * \\
(2.096)\end{array}$ & $\begin{array}{c}0.425^{* *} \\
(2.172)\end{array}$ & $\begin{array}{l}1.502 * * \\
(1.999)\end{array}$ & $\begin{array}{c}0.490^{* *} \\
(2.074)\end{array}$ & $\begin{array}{l}1.480 * * \\
(2.160)\end{array}$ & $\begin{array}{c}0.494 * * \\
(2.228)\end{array}$ \\
\hline Eleições 2012 & $\begin{array}{l}0.712 * \\
(1.759)\end{array}$ & $\begin{array}{c}0.227 * * \\
(1.970)\end{array}$ & $\begin{array}{l}0.787^{*} \\
(1.941)\end{array}$ & $\begin{array}{l}0.249 * * \\
(2.216)\end{array}$ & $\begin{array}{l}0.828^{*} \\
(1.807)\end{array}$ & $\begin{array}{c}0.255^{* *} \\
(2.117)\end{array}$ & $\begin{array}{l}0.796^{*} \\
(1.839)\end{array}$ & $\begin{array}{l}0.251^{* *} \\
(2.123)\end{array}$ & $\begin{array}{l}0.780^{*} \\
(1.771)\end{array}$ & $\begin{array}{c}0.243 * * \\
(2.028)\end{array}$ & $\begin{array}{l}0.849^{*} \\
(1.927)\end{array}$ & $\begin{array}{c}0.264 * * \\
(2.245)\end{array}$ & $\begin{array}{l}0.841^{*} \\
(1.671)\end{array}$ & $\begin{array}{l}0.257 * * \\
(1.972)\end{array}$ & $\begin{array}{l}0.833^{*} \\
(1.770)\end{array}$ & $\begin{array}{c}0.259 * * \\
(2.076)\end{array}$ \\
\hline Eleições 2016 & $\begin{array}{l}-0.140 \\
(-0.346)\end{array}$ & $\begin{array}{c}-0.051 \\
(-0.343)\end{array}$ & $\begin{array}{c}-0.115 \\
(-0.281)\end{array}$ & $\begin{array}{l}-0.042 \\
(-0.279)\end{array}$ & $\begin{array}{c}0.359 \\
(0.785)\end{array}$ & $\begin{array}{c}0.121 \\
(0.835)\end{array}$ & $\begin{array}{c}0.219 \\
(0.520)\end{array}$ & $\begin{array}{c}0.077 \\
(0.535)\end{array}$ & $\begin{array}{l}-0.0839 \\
(-0.194)\end{array}$ & $\begin{array}{c}-0.030 \\
(-0.192)\end{array}$ & $\begin{array}{l}-0.0769 \\
(-0.176)\end{array}$ & $\begin{array}{c}-0.028 \\
(-0.175)\end{array}$ & $\begin{array}{c}0.366 \\
(0.750)\end{array}$ & $\begin{array}{c}0.122 \\
(0.799)\end{array}$ & $\begin{array}{c}0.248 \\
(0.547)\end{array}$ & $\begin{array}{c}0.086 \\
(0.567)\end{array}$ \\
\hline Constante & $\begin{array}{c}1.797 \\
(1.194)\end{array}$ & & $\begin{array}{c}2.047 \\
(1.360)\end{array}$ & & $\begin{array}{c}1.657 \\
(0.974)\end{array}$ & & $\begin{array}{c}2.015 \\
(1.268)\end{array}$ & & $\begin{array}{c}-2.674 \\
(-0.834)\end{array}$ & & $\begin{array}{c}-2.199 \\
(-0.692)\end{array}$ & & $\begin{array}{l}-2.845 \\
(-0.844)\end{array}$ & & $\begin{array}{l}-2.333 \\
(-0.725)\end{array}$ & \\
\hline Observações & 239 & 239 & 239 & 239 & 239 & 239 & 239 & 239 & 239 & 239 & 239 & 239 & 239 & 239 & 239 & 239 \\
\hline $\begin{array}{l}\text { Municípios } \\
\text { LR }\end{array}$ & $\begin{array}{c}187 \\
-149.1\end{array}$ & & $\begin{array}{c}187 \\
-149.9\end{array}$ & & $\begin{array}{c}187 \\
-147.0\end{array}$ & & $\begin{array}{c}187 \\
-147.8\end{array}$ & & $\begin{array}{c}187 \\
-147.8\end{array}$ & & $\begin{array}{c}187 \\
-148.8\end{array}$ & & $\begin{array}{c}187 \\
-146.1\end{array}$ & & $\begin{array}{c}187 \\
-146.7\end{array}$ & \\
\hline $\mathrm{LR}(\mathrm{p})$ & 0.304 & & 0.339 & & 0.277 & & 0.221 & & 0.394 & & 0.437 & & 0.388 & & 0.306 & \\
\hline
\end{tabular}

Notas- Variável Dependente

, que assume o valor 1 caso o prefeito que concorreu à reeleição tenha conseguido atingir o objetivo de ser reeleito, e zero, no caso contrário. - Resultados obtidos segundo 0 método Probit, com Efeitos Aleatórios e com erros-padrão robustos. Efeito Marginal denota os efeitos marginais das variáveis estimadas. - Estatística t entre parênteses.ṣ̌p:- Níveis de significância * $10 \%$, ** $5 \%$ e *** 1\%.LR denota a função de log-verossimilhança.- LR(p) denota o p-valor do teste da razão de máxima verossimilhança. 
Um ponto importante é que os eleitores podem levar em consideração os níveis de despesas durante todo o mandato, e não somente no ano eleitoral. Desta forma, foi estimado o modelo $(i)$ com a média das despesas públicas durante todo o mandato. Os resultados expostos nas Colunas 2 dos Painéis I e II da Tabela 2 levam em consideração a média de despesas orçamentárias durante o mandato governativo e as chances de o prefeito catarinense candidato à reeleição obter um segundo mandato consecutivo. Essa média não parece ter tido influência nos resultados eleitorais.

Depois de ser traçado um panorama de como os eleitores catarinenses reagem às despesas totais empenhadas no ano eleitoral e ao longo do mandato, pode-se migrar para o estudo da eficácia das práticas oportunistas na busca pela reeleição em Santa Catarina.

Os resultados expostos na Coluna 3 do Painel I ${ }^{22}$ da Tabela 2 indicam que sim, o oportunismo tende a compensar, no caso da reeleição dos prefeitos catarinenses. Para cada desvio positivo de um ponto percentual nas despesas empenhadas no ano eleitoral em face da média do mandato executado pelos chefes do Poder Executivo local, houve uma tendência de elevação de, em média, 1,21 ponto percentual na probabilidade de reeleição, ceteris paribus. Esse resultado está alinhado com as evidências empíricas obtidas por Sakurai e MenezesFilho (2008) e Chortareas et al. (2016), que também evidenciaram influências do desvio das despesas orçamentárias nas chances de o político local brasileiro e grego ser reeleito, respectivamente, e de Rogoff e Sibert (1988), que propuseram essa relação.

O mesmo resultado emerge, mesmo que diminuto, quando se analisa a variação entre as despesas empenhadas no primeiro e no último ano de mandato (coluna 4 do Painel I da Tabela 2). Cada variação de um ponto percentual se traduziu num incremento de 0,008 ponto percentual na probabilidade de o prefeito se manter no cargo por mais quatro anos.

A não existência de uma legislação que busque gerar um alisamento das despesas públicas e, assim, evitar que os prefeitos manipulem oportunisticamente as despesas públicas no ano eleitoral, gera, conforme os resultados da Tabela 2, uma assimetria de oportunidades, uma vez que o incumbente, diferentemente dos seus concorrentes, escolhe realizar as despesas nos momentos que considera ser mais facilmente observadas pelos eleitores. Esse movimento de aumentos relativos nas despesas públicas no ano eleitoral, em face da média do mandato,

\footnotetext{
${ }^{22}$ Quando se desmembram as três componentes do IDHM ( Painel II da Tabela 2), a relação causal entre o desvio relativo (Coluna 3 do Painel II da Tabela 2) de um ponto percentual das despesas totais empenhadas no ano eleitoral, em face da média de mercado, é de, aproximadamente, 1,22 ponto percentual na probabilidade de reeleição, ceteris paribus.
} 
irá gerar uma futura necessidade de recursos, o que poderá frustrar as despesas nos próximos períodos. Essas dinâmicas de aumento e posterior redução nas despesas públicas é que geram um ciclo orçamentário coincidente com o calendário das eleições e que podem gerar ineficiências econômicas, pois alteram as expectativas dos agentes econômicos.

Analisando agora como as variáveis de controle se relacionam com a probabilidade de reeleição, os resultados expostos na Tabela 2 sugerem que, nos municípios catarinenses cuja população apresenta maiores níveis de desenvolvimento humano (IDHM), os eleitores são menos propensos a reelegerem seus prefeitos, nomeadamente nas duas estimações do modelo $i$ que não estão relacionadas ao oportunismo, e sim, respectivamente, aos níveis de despesa pública empenhada no ano eleitoral (Coluna 1 do Painel I da Tabela 2) e a média das despesas empenhadas durante o mandato do prefeito (Coluna 2 do Painel I da Tabela 2). ${ }^{23}$

No Painel II da Tabela 2, em vez do IDHM como variável explicativa, as suas três componentes (educação, renda e longevidade) estão expressas em separado, permitindo-se, assim, observar qual dos indicadores é o mais relevante para explicar a relação entre o IDHM e a probabilidade de reeleição. Esses resultados, expostos no Painel II da Tabela 2, indicam que é somente o índice de desenvolvimento humano municipal relacionado à educação que influencia negativamente a probabilidade de reeleição dos prefeitos. Ou seja, os municípios catarinenses com maiores IDHM_E, tendem, em média, a reeleger menos os seus prefeitos. Já os índices de desenvolvimento humano renda e longevidade não parecem ter relação causal com a probabilidade de reeleição.

Ainda sobre a demografia, a proporção de população urbana não foi possível constatar relação causal significante com a probabilidade de reeleição nos municípios catarinenses, ou seja, o da localidade ser mais/menos rural, não altera as chances de reeleição do prefeito. Os resultados estimados neste trabalho (Tabela 2) sugerem, em algumas estimações, que o percentual de votos do prefeito na eleição anterior é positivamente relacionado à probabilidade de reeleição. Esse resultado indica que o patrimônio eleitoral tende a ter uma relação direta com a probabilidade de reeleição ${ }^{24}$, ou seja, os que apresentam mais votos na sua primeira eleição conseguem fidelizar parte desse eleitorado e, assim, apresentam maiores chances de se manterem no poder por mais quatro anos.

\footnotetext{
${ }^{23} \mathrm{~A}$ análise da relação entre desenvolvimento humano, oportunismo e probabilidade de reeleição, só poderá ser realizado quando a amostra for particionada.

${ }^{24}$ Para fins de comparação Veiga e Veiga (2007), Arvate et al. (2010), Drazen e Eslava (2010) e Aidt et al. (2011), constataram uma relação entre margem de vitória e a probabilidade do político local ser reeleito, sendo que a margem é a diferença entre os votos recebidos pelo primeiro e segundo colocados.
} 
Ao analisar se a ideologia e o alinhamento do prefeito em níveis mais elevados de governo influenciam na decisão do eleitor catarinense de reeleger ou não o seu prefeito, o fato de este ser de um partido de esquerda não teve influência significativa sobre a possibilidade de ser reeleito.

O alinhamento ao governador do estado, na segunda metade do governo, assim como alinhamento ao presidente da República, também não foi possível evidenciar uma relação com as chances de reeleição. Este resultado diverge das concussões obtidas, para os municípios brasileiros, por Meneguin et al. (2005), que evidenciaram, nas eleições locais de 2000, um impacto do alinhamento ao presidente da República, mas não ao governador do estado, sendo que os prefeitos do mesmo partido do chefe da nação apresentaram maiores chances de obter a reeleição. Já Sakurai e Menezes-Filho (2008), ao analisarem a mesma eleição de 2000, encontraram evidências de que ambos os alinhamentos tiveram impacto. Mas, quando analisaram o período de 1988 até 2000, concluíram que somente o fato de o prefeito ser do mesmo partido que o do presidente diminuiu as chances de do partido se manter à frente do poder. Aidt et al. (2011) constataram que os prefeitos portugueses do mesmo partido que o do governo central são penalizados nas eleições.

Por fim, neste exercício empírico, a variável funciona como uma proxy do nível da atividade econômica no ano com eleições e se mostra estatisticamente significativa (5\% e $10 \%$ de significância) e positivamente relacionada à probabilidade de reeleição. Esse resultado é oposto ao proposto por Rogoff e Sibert (1988), pois, para estes, maiores arrecadações no ano eleitoral não são medidas oportunistas, ou seja, não deveriam ser bem recebidas pela população. Entretanto, como a LRF exige que para toda despesa empenhada no ano com eleição haja a sua respectiva fonte de financiamento indicada na peça orçamentária, faz com que os prefeitos que decidam elevar as suas despesas em anos com eleições tenham de financiar esses dispêndios com elevação dos tributos, pois as operações de crédito também apresentam limitações.

\section{Composição da despesa e reeleição}

Rogoff (1990) argumenta que os incumbentes, buscando a manutenção do poder, podem alterar a composição da despesa, destinando mais recursos aos gastos de maior visibilidade, com a finalidade de sinalizar aos eleitores a sua competência à frente do governo. Para analisar se os eleitores catarinenses agem perante as diferentes rubricas da despesa pública, serão analisadas as despesas com pessoal e com investimentos. 
Tabela 3 - Despesas com pessoal e investimentos empenhados e a probabilidade de reeleição

\begin{tabular}{|c|c|c|c|c|c|c|c|c|c|c|c|c|c|c|c|c|}
\hline \multirow{5}{*}{ VARIÁVEIS } & \multirow{2}{*}{\multicolumn{8}{|c|}{ Painel I }} & \multirow{2}{*}{\multicolumn{8}{|c|}{ Painel II }} \\
\hline & & & & & & & & & & & & & & & & \\
\hline & \multirow{2}{*}{\multicolumn{2}{|c|}{$\begin{array}{c}(1) \\
\text { Eleitoral }\end{array}$}} & \multirow{2}{*}{\multicolumn{2}{|c|}{$\begin{array}{c}\text { (2) } \\
\text { Mandato }\end{array}$}} & \multirow{2}{*}{\multicolumn{2}{|c|}{$\begin{array}{c}\text { (3) } \\
\text { Desvio }\end{array}$}} & \multicolumn{2}{|c|}{ (4) } & \multirow{2}{*}{\multicolumn{2}{|c|}{$\begin{array}{c}\text { (1) } \\
\text { Eleitoral }\end{array}$}} & \multirow{2}{*}{\multicolumn{2}{|c|}{$\begin{array}{c}\text { (2) } \\
\text { Mandato }\end{array}$}} & \multirow{2}{*}{\multicolumn{2}{|c|}{$\begin{array}{c}\text { (3) } \\
\text { Desvio }\end{array}$}} & \multirow{2}{*}{\multicolumn{2}{|c|}{$\begin{array}{c}(4) \\
\text { Variacão }\end{array}$}} \\
\hline & & & & & & & Variação & Variação & & & & & & & & \\
\hline & Probit & $\begin{array}{c}\text { Efeito } \\
\text { Marginal }\end{array}$ & Probit & $\begin{array}{c}\text { Efeito } \\
\text { Marginal }\end{array}$ & Probit & $\begin{array}{c}\text { Efeito } \\
\text { Marginal }\end{array}$ & Probit & $\begin{array}{c}\text { Efeito } \\
\text { Marginal }\end{array}$ & Probit & $\begin{array}{c}\text { Efeito } \\
\text { Marginal }\end{array}$ & Probit & $\begin{array}{c}\text { Efeito } \\
\text { Marginal }\end{array}$ & Probit & $\begin{array}{c}\text { Efeito } \\
\text { Marginal }\end{array}$ & Probit & $\begin{array}{c}\text { Efeito } \\
\text { Marginal }\end{array}$ \\
\hline Pessoal & $\begin{array}{c}-0.285 \\
(-1.016)\end{array}$ & $\begin{array}{l}-0.091 \\
(-1.030)\end{array}$ & $\begin{array}{c}-0.329 \\
(-1.016)\end{array}$ & $\begin{array}{c}-0.112 \\
(-1.031)\end{array}$ & $\begin{array}{c}-0.0776 \\
(-0.0541)\end{array}$ & $\begin{array}{c}-0.025 \\
(-0.054)\end{array}$ & $\begin{array}{l}0.00247 \\
(0.166)\end{array}$ & $\begin{array}{c}0.001 \\
(0.166)\end{array}$ & $\begin{array}{c}-0.235 \\
(-0.841)\end{array}$ & $\begin{array}{c}-0.074 \\
(-0.848)\end{array}$ & $\begin{array}{c}-0.294 \\
(-0.900)\end{array}$ & $\begin{array}{l}-0.099 \\
(-0.912)\end{array}$ & $\begin{array}{c}0.0576 \\
(0.0401)\end{array}$ & $\begin{array}{c}0.019 \\
(0.040)\end{array}$ & 0.00426 & $\begin{array}{c}0.001 \\
(0283)\end{array}$ \\
\hline Investimento & $\begin{array}{c}1.924 * * * \\
(3.367)\end{array}$ & $\begin{array}{c}0.613^{* * *} \\
(4.004)\end{array}$ & $\begin{array}{l}1.424 * * \\
(2.027)\end{array}$ & $\begin{array}{l}0.486^{* *} \\
(2.135)\end{array}$ & $\begin{array}{l}0.654 * * \\
(2.261)\end{array}$ & $\begin{array}{l}0.215^{* *} \\
(2.473)\end{array}$ & $\begin{array}{c}0.000884 \\
(0.799)\end{array}$ & $\begin{array}{c}0.000 \\
(0.806)\end{array}$ & $\begin{array}{c}1.928 * * * \\
(3.317)\end{array}$ & $\begin{array}{c}0.608 * * * \\
(3.936)\end{array}$ & $\begin{array}{l}1.498^{* *} \\
(2.064)\end{array}$ & $\begin{array}{l}0.504 * * \\
(2.185)\end{array}$ & $\begin{array}{l}0.656^{* *} \\
(2.282)\end{array}$ & $\begin{array}{l}0.214 * * \\
(2.486)\end{array}$ & $\begin{array}{c}0.000947 \\
(0.850)\end{array}$ & $\begin{array}{c}0.000 \\
(0.857)\end{array}$ \\
\hline Observações & 239 & 239 & 239 & 239 & 239 & 239 & 239 & 239 & 239 & 239 & 239 & 239 & 239 & 239 & 239 & 239 \\
\hline Município & 187 & & 187 & & 187 & & 187 & & 187 & & 187 & & 187 & & 187 & \\
\hline clustvar & Codigo & & Codigo & & Codigo & & Codigo & & Codigo & & Codigo & & Codigo & & Codigo & \\
\hline LR & -141.1 & & -147.2 & & -147.0 & & -149.8 & & -140.1 & & -146.1 & & -146.0 & & -148.8 & \\
\hline $\mathrm{LR}(\mathrm{p})$ & 0.105 & & 0.286 & & 0.351 & & 0.431 & & 0.167 & & 0.390 & & 0.437 & & 0.524 & \\
\hline
\end{tabular}

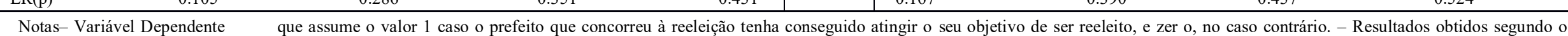

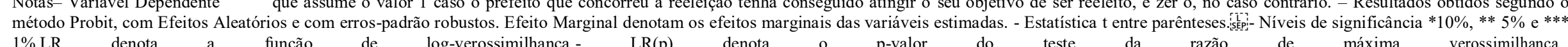
$1 \%$.LR $\operatorname{LR}(\mathrm{p}) \quad$ denota o p-valor do $\quad$ teste da
da de máxima verossimilhança.
ver 
Quando são analisadas as despesas com pessoal e investimento (Tabela 3), percebe-se que os investimentos, tanto no ano eleitoral como a média do mandato, apresentam um impacto positivo e significativo sobre as chances de o prefeito catarinense obter mais um mandato à frente da prefeitura.

Conforme indicam os resultados expostos nas colunas 1 e 2 de ambos os Painéis I e II da Tabela 3, os prefeitos que empenharam mais investimentos no ano eleitoral viram suas chances de obter um segundo mandato à frente do poder local se elevar. Para cada aumento de mil reais per capita nos investimentos empenhados no ano com eleições, há um incremento, em média, de aproximadamente 0,61 ponto percentual na probabilidade de o prefeito obter a reeleição, ceteris paribus. Os resultados para os investimentos em anos eleitorais corroboram os resultados obtidos por Meneguin et al (2005), para os governos locais brasileiros, e os de Veiga e Veiga (2007), para as municipalidades portuguesas, uma vez que maiores níveis de dispêndios com investimentos nos anos com eleições elevam as chances de o governante obter mais um mandato à frente do poder local. Já o montante de despesas com pessoal empenhada no ano eleitoral não parece ter impacto sobre as probabilidades de reeleição.

Quando se analisa a média dos investimentos durante o mandato, percebe-se que, da mesma forma que os montantes empenhados durante o ano eleitoral, as despesas com investimento têm impacto estatisticamente significativo e positivo sobre a chance de reeleição ${ }^{25}$. Para cada aumento de mil reais per capita, o incumbente vê sua probabilidade de reeleição se elevar em aproximadamente 0,50 ponto percentual, em média, todo o resto constante.

Focando agora na eficácia do oportunismo na alteração da composição da despesa, observa-se que os municípios cujos prefeitos desviaram mais os investimentos do ano eleitoral, em face da média do mandato, tiveram uma elevação de, em média, 0,21 ponto percentual para cada desvio de um ponto percentual. Esse resultado ${ }^{26}$ indica que prefeitos oportunistas nas despesas com investimento são recompensados nas urnas. Ou seja, o fato de o prefeito mostrar, em sua campanha, as obras e investimentos realizados durante a administração, tornou-o bem recebido pelos eleitores catarinenses. Por outro lado, o fato de o

\footnotetext{
${ }^{25}$ Esses resultados estão alinhados com as conclusões de Balaguer-Coll et al. (2015), que também dividiram as despesas entre diferentes períodos durante o mandato e constataram que os eleitores espanhóis recompensam os prefeitos que gastam mais, especialmente os que apresentam maiores níveis de despesas de capital ao longo do mandato

${ }^{26}$ Os resultados de Chortareas et al. (2016) para os municípios gregos, o desvio nos investimentos não aumenta nem diminui a probabilidade de o político se manter no poder.
} 
prefeito catarinense apresentar maior variação relativa entre os investimentos empenhados no primeiro ano do mandato e o ano eleitoral não elevou as chances de reeleição do chefe do Poder Executivo local.

Ainda sobre a eficácia da adoção de práticas oportunistas, os resultados contidos na Tabela 3 indicam que desviar mais as despesas com pessoal empenhadas no ano eleitoral, em face da média do mandato, assim como apresentar maior variação entre o primeiro e último ano do mandato, não surtiu nenhuma influência sobre a probabilidade de reeleição. Esse resultado para as despesas com pessoal já era esperado, especialmente devido à existência, na LRF, de limitações claras quanto à dinâmica dessas rubricas em anos com eleições. A LRF gerou um alisamento das despesas com pessoal, impedindo que os incumbentes elevassem essa componente antes das eleições, não permitindo, assim, que os prefeitos sinalizem a sua competência por meio delas. Em decorrência disso, não foi possível constatar uma relação entre despesas com pessoal e a probabilidade de reeleição.

Por outro lado, os investimentos que não têm impedimentos legais à sua elevação antes das eleições podem ser utilizados livremente como instrumento de sinalização da competência do prefeito, mesmo que, no futuro, os cidadãos venham a ser chamados a pagar por eles. A possibilidade, permitida também na LRF, de financiamento dos investimentos em anos eleitorais com operações de crédito torna possível que os prefeitos invistam antes dos pleitos municipais e paguem essas despesas somente após as votações.

\section{Recortes}

Depois de traçado o panorama, cujos resultados indicam uma relação inversa entre o nível de desenvolvimento humano e a probabilidade de reeleição dos prefeitos, é interessante estimar novamente o modelo (i), mas agora somente com duas subamostras: uma composta pelos municípios catarinenses considerados de alto e muito alto nível de desenvolvimento humano (IDHM $\geq 0,725^{27}$ ) e os com muito baixo, baixo e médio nível de desenvolvimento humano (IDHM $<0,725$ ).

\footnotetext{
${ }^{27}$ Utiliza-se, geralmente, o limiar de 0,7 para determinar que um município é de alto nível de desenvolvimento humano, contudo, ao se utilizar essa marca, a divisão da amostra fica desequilibrada, uma vez que a maioria dos municípios catarinenses tem IDHM superior a 0,7. Posto isso, para que houvesse duas amostras com número de observações mais equilibrado e, ainda assim, representativas do grau de desenvolvimento humano, decidiu-se, sem perdas à análise, utilizar o limiar de 0,725 , no qual os municípios com esse valor, ou superior, foram considerados de alto ou muito alto nível de desenvolvimento, e com IDHM menor de 0,725, de médio, baixo e muito baixo nível de desenvolvimento humano.
} 
Tabela 4 - Despesas públicas empenhadas e a probabilidade de reeleição (Recortes)

\begin{tabular}{|c|c|c|c|c|c|c|c|c|c|}
\hline \multirow{3}{*}{\multicolumn{2}{|c|}{ Notas-- }} & \multicolumn{4}{|c|}{ IDHM $>=0.725$} & \multicolumn{4}{|c|}{ IDHM $<0.725$} \\
\hline & & \multicolumn{2}{|c|}{ (1) } & \multicolumn{2}{|c|}{ (2) } & \multicolumn{2}{|c|}{ (3) } & \multicolumn{2}{|c|}{ (4) } \\
\hline & & Probit & $\begin{array}{c}\text { Efeito } \\
\text { Marginal }\end{array}$ & Probit & $\begin{array}{c}\text { Efeito } \\
\text { Marginal }\end{array}$ & Probit & $\begin{array}{c}\text { Efeito } \\
\text { Marginal }\end{array}$ & Probit & $\begin{array}{c}\text { Efeito } \\
\text { Marginal }\end{array}$ \\
\hline & DespesaDesvio & $\begin{array}{c}10.45^{* * *} \\
(2.141)\end{array}$ & $\begin{array}{c}3.176 * * * \\
(2.941)\end{array}$ & & & $\begin{array}{c}2.218 \\
(1.215)\end{array}$ & $\begin{array}{c}0.722 \\
(1.282)\end{array}$ & & \\
\hline & DespesaVariacao & & & $\begin{array}{c}0.0294 \\
(1.267)\end{array}$ & $\begin{array}{c}0.010 \\
(1.370)\end{array}$ & & & $\begin{array}{l}0.0239 \\
(1.449)\end{array}$ & $\begin{array}{c}0.008 \\
(1.572)\end{array}$ \\
\hline & TributosE & $\begin{array}{c}1.664 \\
(0.909)\end{array}$ & $\begin{array}{c}0.506 \\
(0.965)\end{array}$ & $\begin{array}{c}2.340 \\
(1.302)\end{array}$ & $\begin{array}{c}0.772 \\
(1.439)\end{array}$ & $\begin{array}{c}-0.643 \\
(-0.334)\end{array}$ & $\begin{array}{c}-0.209 \\
(-0.337)\end{array}$ & $\begin{array}{c}-0.538 \\
(-0.281)\end{array}$ & $\begin{array}{c}-0.174 \\
(-0.283)\end{array}$ \\
\hline & Urbano & $\begin{array}{c}-0.477 \\
(-0.384)\end{array}$ & $\begin{array}{l}-0.145 \\
(-0.389)\end{array}$ & $\begin{array}{l}-0.787 \\
(-0.629)\end{array}$ & $\begin{array}{c}-0.260 \\
(-0.646)\end{array}$ & $\begin{array}{c}-0.312 \\
(-0.413)\end{array}$ & $\begin{array}{c}-0.101 \\
(-0.414)\end{array}$ & $\begin{array}{c}-0.134 \\
(-0.183)\end{array}$ & $\begin{array}{c}-0.044 \\
(-0.183)\end{array}$ \\
\hline & Percentagem & $\begin{array}{c}2.702 \\
(1.316)\end{array}$ & $\begin{array}{c}0.821 \\
(1.418)\end{array}$ & $\begin{array}{c}2.634 \\
(1.177)\end{array}$ & $\begin{array}{c}0.869 \\
(1.255)\end{array}$ & $\begin{array}{c}0.966 \\
(0.837)\end{array}$ & $\begin{array}{c}0.315 \\
(0.836)\end{array}$ & $\begin{array}{c}0.991 \\
(0.846)\end{array}$ & $\begin{array}{c}0.322 \\
(0.849)\end{array}$ \\
\hline & Esquerda & $\begin{array}{l}5.754 * * \\
(2.309)\end{array}$ & $\begin{array}{c}1.748^{* * * *} \\
(3.115)\end{array}$ & $\begin{array}{l}5.817 * * \\
(2.421)\end{array}$ & $\begin{array}{c}1.919 * * * \\
(3.032)\end{array}$ & $\begin{array}{c}-7.169 * * * \\
(-3.509)\end{array}$ & $\begin{array}{c}-2.335 * * * \\
(-5.268)\end{array}$ & $\begin{array}{c}-7.215^{* * *} \\
(-3.464)\end{array}$ & $\begin{array}{c}-2.341 * * * \\
(-5.164)\end{array}$ \\
\hline & Pres2 & $\begin{array}{c}- \\
4.816^{* *} \\
(-2.122)\end{array}$ & $-1.463^{* *}$ & $\begin{array}{c}- \\
4.686^{* *} \\
(-2.194)\end{array}$ & $\begin{array}{l}-1.546 * * \\
(-2.531)\end{array}$ & $\begin{array}{c}6.754 * * * \\
(3.472)\end{array}$ & $\begin{array}{c}2.200 * * * \\
(5.042)\end{array}$ & $\begin{array}{c}6.800 * * * \\
(3.408)\end{array}$ & $\begin{array}{c}2.206^{* * *} \\
(4.917)\end{array}$ \\
\hline & Gov2 & $\begin{array}{c}0.498 \\
(0.950)\end{array}$ & $\begin{array}{c}0.151 \\
(1.012)\end{array}$ & $\begin{array}{c}0.410 \\
(0.742)\end{array}$ & $\begin{array}{c}0.135 \\
(0.775)\end{array}$ & $\begin{array}{c}0.173 \\
(0.590)\end{array}$ & $\begin{array}{c}0.056 \\
(0.593)\end{array}$ & $\begin{array}{l}0.0735 \\
(0.242)\end{array}$ & $\begin{array}{c}0.024 \\
(0.241)\end{array}$ \\
\hline & Constant & $\begin{array}{c}-2.533 \\
(-1.476)\end{array}$ & & $\begin{array}{l}-1.810 \\
(-1.065)\end{array}$ & & $\begin{array}{c}-0.0482 \\
(-0.0645)\end{array}$ & & $\begin{array}{c}-0.0692 \\
(-0.0912)\end{array}$ & \\
\hline & Observações & 74 & 74 & 74 & 74 & 165 & 165 & 165 & 165 \\
\hline & Município & 68 & & 68 & & 146 & & 146 & \\
\hline & Clustvar & Codigo & & Codigo & & Codigo & & Codigo & \\
\hline & LR & -40.93 & & -44.24 & & -101.4 & & -100.8 & \\
\hline & $\mathrm{LR}(\mathrm{p})$ & 0.828 & & 0.853 & & 0.850 & & 0.808 & \\
\hline
\end{tabular}

Dependente , que assume o valor 1 caso o prefeito que concorreu à reeleição tenha conseguido atingir o seu objetivo de ser reeleito, e zero, no caso contrário. - Resultados obtidos segundo o método Probit com efeitos aleatórios e com erros-padrão robustos. Efeito Marginal denotam os efeitos marginais das variáveis estimadas. - Estatística t entre parênteses.iṣ̌̂̉- Níveis de significância * $10 \%$, ** 5\% e *** $1 \%$.LR denota a função de log-verossimilhança.- LR(p) denota o p-valor do teste da razão de máxima verossimilhança.

Com esses recortes, consegue-se, agora, capturar a possível influência do IDHM sobre a eficácia da adoção de medidas ditas oportunistas, como o desvio das despesas empenhadas no ano eleitoral, em face da média do mandato (colunas 1 e 3 da Tabela 4) e a variação entre o primeiro e o último ano do mandato (colunas 2 e 4 da Tabela 4).

Os resultados contidos na Tabela 4 sugerem que o oportunismo nos moldes de Rogoff e Sibert (1988) só é, tudo o resto constante, recompensado pela população dos municípios com IDHM igual ou superior a 0,725 , indicando que o fato de o município ser desenvolvido não impede que a população premie os desvios nas despesas totais no ano eleitoral, em face da média do mandato. Para cada desvio relativo de um ponto percentual nas despesas totais do ano eleitoral, em face da média do mandato, há uma elevação de 3,17 pontos percentuais na probabilidade de reeleição.

Quando se migrando para as despesas com pessoal e os investimentos, novamente apenas os municípios com IDHM igual ou superior a 0,75 recompensam medidas oportunista. O desvio relativo um ponto percentual nos investimentos empenhados no ano eleitoral, em 
face da média do mandato, acarreta, em média, um aumento de 0,37 ponto percentual na probabilidade de reeleição, ceteris paribus.

Tabela 5 - Despesas com pessoal e investimentos empenhados e a probabilidade de reeleição (Recortes)

\begin{tabular}{|c|c|c|c|c|c|c|c|c|}
\hline & \multicolumn{2}{|c|}{ (1) } & \multicolumn{2}{|c|}{ (2) } & \multicolumn{2}{|c|}{ (3) } & \multicolumn{2}{|c|}{ (4) } \\
\hline & \multicolumn{4}{|c|}{ IDHM $>=0.725$} & \multicolumn{4}{|c|}{ IDHM $<0.725$} \\
\hline Variáveis & Probit & $\begin{array}{c}\text { Efeito } \\
\text { Marginal }\end{array}$ & Probit & $\begin{array}{c}\text { Efeito } \\
\text { Marginal }\end{array}$ & Probit & $\begin{array}{c}\text { Efeito } \\
\text { Marginal }\end{array}$ & Probit & $\begin{array}{c}\text { Efeito } \\
\text { Marginal }\end{array}$ \\
\hline Pessoal Desvio & 2.778 & 0.878 & & & -0.0538 & -0.0174 & & \\
\hline & $(0.718)$ & $(0.717)$ & & & $(-0.0320)$ & $(-0.0321)$ & & \\
\hline Investimento Desvio & $1.185^{*}$ & $0.375^{* *}$ & & & 0.356 & 0.115 & & \\
\hline & $(1.686)$ & $(2.052)$ & & & $(0.968)$ & $(1.025)$ & & \\
\hline Pessoal Variacao & & & 0.0266 & 0.009 & & & -0.00178 & -0.000595 \\
\hline & & & $(0.866)$ & $(0.884)$ & & & $(-0.0948)$ & $(-0.0949)$ \\
\hline Investimento Variacao & & & 0.00317 & 0.001 & & & $3.22 \mathrm{e}-05$ & $1.07 \mathrm{e}-05$ \\
\hline & & & $(1.231)$ & $(1.287)$ & & & $(0.0256)$ & $(0.0256)$ \\
\hline Observações & 74 & 74 & 74 & 74 & 165 & 165 & 165 & 165 \\
\hline Município & 68 & & 68 & & 146 & & 146 & \\
\hline Clustvar & Codigo & & Codigo & & Codigo & . & Codigo & . \\
\hline LR & -42.74 & & -43.98 & & -101.6 & . & -102.2 & . \\
\hline LR(p) & 0.869 & & 0.808 & & 0.929 & . & 0.911 & . \\
\hline
\end{tabular}

Notas- Variável Dependente

. que assume o valor 1 caso o prefeito que concorreu à reeleição tenha conseguido atingir $o$ objetivo de ser reeleito, e zero, no caso contrário - Resultados obtidos segundo o método Probit com efeitos aleatórios e com erros padrão robustos. Efeito Marginal denotam os efeitos marginais das variáveis estimadas. - Estatística t entre parênteses.j: $* 10 \%, * * 5 \%$ e *** 1\%.LR denota a função de log-verossimilhança.- LR(p) denota o p-valor do teste da razão de máxima verossimilhança.

A possível explicação para o oportunismo só ser recompensado pelos eleitores dos municípios de IDHM elevado reside no fato de que, provavelmente, nessas localidades os prefeitos conseguem, de maneira mais efetiva que nas menos desenvolvidas, sinalizar de maneira mais eficiente a sua competência, tanto via aumento nas despesas públicas antes das eleições, conforme descrito por Rogoff e Sibert (1988), como via aumento relativo dos investimentos em face da média do mandato, da mesma maneira que Rogoff (1990) propôs.

\section{CONCLUSÕES}

Esse artigo propôs analisar como o eleitor catarinense age perante os níveis de despesas públicas e a sua composição. Evidenciou-se que o oportunismo ainda compensa em Santa Catarina. Prefeitos que relativamente mais desviam as despesas do ano eleitoral, em face da média do mandato, e que apresentam maiores variações relativas entre o primeiro e último ano do mandato, têm maiores chances de se manterem no poder.

Dois resultados interessantes são a relação direta entre a probabilidade de reeleição e as despesas tributárias, e a relação inversa com tempo médio de estudo da população. O primeiro indica que, possivelmente, os eleitores ou não conseguem observar de maneira fácil os níveis 
de receitas tributárias no ano eleitoral -, pois quanto maior a arrecadação, maiores as chances de reeleição - , ou, então, relevam esse aumento, pois há uma elevação nas despesas, o que compensaria, na visão do eleitorado, o peso dos tributos. Considerando o resultado obtido por Lautenschlage (2016), a resposta mais acertada é o fato dos prefeitos preferirem elevar os tributos indiretos, o que dificulta a sua percepção por parte do eleitorado. Para novas investigações, seria prudente partir as receitas em tributos diretos e indiretos, o que permitiria uma maior compreensão desse fenômeno.

Fica evidente que os investimentos são os dispêndios mais bem recebidos pelos eleitores nas eleições locais catarinenses entre 2005 e 2016. Os prefeitos que mais despenderam com essas rubricas viram suas chances reeleição serem elevadas, tanto quando se consideram os níveis gastos durante o ano eleitoral, como durante todo o mandato. Fenômeno semelhante se verificou com os que mais desviaram os investimentos no ano eleitoral em face da média do mandato. Desta forma, aumentar as despesas públicas antes das eleições tende a ampliar as probabilidades de reeleição do prefeito em Santa Catarina, especialmente se o governante elevar os investimentos.

As despesas com pessoal não tiveram, segundo os resultados estimados, influência sobre as probabilidades de reeleição. Contudo, deve-se levar em consideração a existência da Lei de Responsabilidade Fiscal, que versa sobre as despesas com pessoal e impõe balizas a elas, mas não sobre os investimentos. Desta forma, ao não estabelecerem parâmetros para esta rubrica, especialmente em anos com eleições, não foi eliminada a possibilidade de haver manipulações oportunistas nos investimentos. Esta lacuna na LRF pode ser a explicação para que o oportunismo nas despesas totais também tenha uma relação positiva e significativa sobre a probabilidade de reeleição.

O fato da LRF permitir que os prefeitos se utilizem de recursos oriundos de operações de crédito para financiarem investimentos nos anos eleitorais faz com que a dinâmica de elevação nessas despesas antes das votações, e consequente diminuição nos períodos seguintes, o que gera um ciclo no orçamento com base no calendário eleitoral, ainda se perpetue, privilegiando os incumbentes em detrimento à economia. Posto isso, uma alteração na LRF, no sentido de instituir um alisamento nos investimentos e nas demais componentes da despesa pública, reduzirá manipulações como as constatadas por Lautenschlage (2018).

Já a relação inversa entre o índice de desenvolvimento humano municipal (IDHM) e a sua componente referente ao nível de desenvolvimento na educação (IDHM_E) e a probabilidade de reeleição indica que municípios com mais eleitores instruídos, ou seja, com 
maior capital humano, estão menos inclinados a reelegerem os seus prefeitos incumbentes. Esse resultado poderia sugerir que, possivelmente, os eleitores de localidades mais desenvolvidas são menos propensos à manipulação do oportunismo eleitoral. Entretanto, os resultados obtidos pelos recortes são muito interessantes e permitiram capturar o comportamento dos catarinenses em face das medidas oportunistas (desvios e variações relativas) em nível da despesa total e da sua composição, sugerindo que o oportunismo é recompensado somente pela população dos municípios mais desenvolvidos, ou seja, os de IDHM superior à 0,75 . Esse resultado indica que os eleitores das localidades mais desenvolvidas conseguem observar melhor as elevações das despesas totais e dos investimentos no ano eleitoral, em face da média do mandato e, assim, tendam a reeleger mais os seus governantes.

Para estudos futuros, é pertinente analisar as despesas classificadas segundo a classificação funcional, o que poderá dar uma visão mais aprofundada das rubricas que são mais bem recebidas pelos eleitores na hora de decidirem se darão, ou não, um novo mandato ao incumbente.

\section{REFERÊNCIAS BIBLIOGRÁFICAS}

AIDT, T.S.; VEIGA, F.J.; VEIGA, L.G. "Election results and opportunistic policies: a new test of the rational political business cycle model”. Public Choice, n. 148, p. 21-44, 2011.

AKHMEDOV, A.; ZHURAVSKAYA, E. "Opportunistic political cycles: test in a young democracy setting”. Quarterly Journal of Economics, n. 119, p. 1301-1338, 2004.

ALESINA, A.; TROIANO, U.; CASSIDY, T. “Old and young politicians". NBER Working Paper, 20977, 2015.

ARVATE, P. R.; AVELINO, G.; TAVARES, J. "Fiscal conservatism in a new democracy: “sophisticated versus naive" voters". Economics Letters, n.102, p. 125-127, 2009.

ARVATE, P.; MENDES, M.; ROCHA, A. "Are voters fiscal conservatives? evidence from brazilian municipal elections”. Estudos Econômicos, v.40, n. 1, p.67-101, 2010.

BALAGUER-COLL, M. T.; BRUN-MARTOS, M. I.; FORTE, A.; TORTOSA-AUSINA, E. 'Local governments' re-election and its determinants: New evidence based on a Bayesian approach”. European Journal of Political Economy, n. 39, p. 94-108, 2015. 
BRASIL. Lei Complementar $n^{\circ} 101$, de 04 de maio de 2000.

BRENDER, A. "The effect of fiscal performance on local government election results in Israel: 1989-1998”. Jornal of Public Economics. n. 87, p. 2187-2205, 2003.

BRENDER, A.; DRAZEN, A. "How Do Budget Deficits and Economic Growth Affect Reelection Prospects? Evidence from a Large Cross-Section of Countries". American Economic Review, n. 98, p. 2203-2220, 2008.

CAVALCANTE, P. "Desempenho fiscal e eleiç es no Brasil: uma an lise comparada dos governos municipais”. Revista de Administração Pública, v. 50, n. 2, p. 307-330, 2016

CHORTAREAS, G.; LOGOTHETIS, V.; PAPANDREOU, A. A. "Political budget cycles and reelection prospects in Greece's municipalities". European Journal of Political Economy, n. 43 , p. $1-13,2016$.

CIOFFI, M.; MESSINA, G.; TOMMASINO, P. Parties, institutions and political budget cycles at municipal level: evidence from Italy. MIMEO, 2012.

DAVIDSON, R.; MACKINNON, J. G. Econometric theory and methods. New York: Oxford University Press, 1999.

DRAZEN, A., ESLAVA, M. "Electoral manipulation via voter-friendly spending: theory and evidence". Jornal of development economics, n.92, p.39-52, 2010.

ENKELMANN, S.; LEIBRECHT, M. "Political expenditure cycles and election outcomes: evidence from disaggregation of public expenditures by economic functions". Economics Letters, n.121, p.128-132, 2013.

GREENE, W. Econometric analysis. 7th ed. London: Pearson, 2012.

JONES, M. P.; MELONI, O.; TOMMASI, M. "Voters as fiscal liberals: incentives and accountability in federal systems”. Economics \& Politics, v. 24, n. 2, p. 135-156, 2012.

KLEIN, F. A. "Reelection incentives and political budget cycle: evidence from Brazil". Revista de Administração Pública, v. 44, n. 2, p. 283-337, 2010.

LAUTENSCHLAGE, J. "Ciclo político-econômicos nos municípios de Santa Catarina”. 
Textos de economia. v.21, n.1, p. 1-24, 2018.

MAINWARING, S. P. Rethinking party systems in the third wave of democratization: the case of Brazil. Stanford University Press, 1999.

MENEGUIN, F. B.; BUGARIN, M. S.; CARVALHO, A. X. Texto para discussão "O que leva um governante à reeleição". IPEA, nº 1135, 2005.

NORDHAUS, W. "The polítical business cycle”. Review of Economic Studies, n. 42, p. 169190, 1975.

PELZMAN, S. "Voters as Fiscal Conservatives". Quarterly Journal of Economics, n. 57, p. 327-361, 1992.

ROGOFF, K. "Equilibrium polítical budget cycles". American Economic Review, n. 80, p. 2136, 1990.

ROGOFF, K.; SIBERT, A. "Elections and macroeconomic policy cycles". Review of Economics Studies, n. 55, p. 1-16, 1988.

SAKURAI, S. N.; MENEZES-FILHO, N. A. "Fiscal policy and reelection in Brazilian municipalities". Public Choice, n. 137, p. 301-314, 2008.

SEDMIHRADSKA, L.; KUBIK, R., HAAS, J. "Political bussiness cycles in Czech Municipalities”. Economic Papers, v. 20, n. 1, p. 59-70, 2011.

SJAHRIR, B. S.; KIS-KATOS, K.; SCHULZE, G. G. "Political budget cycles in Indonesia at the discrict level". Economics Letters, n. 120, p. 342-345, 2013.

VEIGA. L. G. "Voting functions in the EU-15". Public Choice, n. 157, p. 411-428, 2013.

VEIGA. L. G; VEIGA, F. J. "Polítical business cycles at the municipal level”. Public Choice, n. 131, p.45-64, 2007.

VERBEEK, M. A Guide to Modern Econometrics, John Wiley \& Sons, Ltd.: Chichester, England, 2008. 
ZUCCO, C. "Esquerda, Direita e Governo: A Ideologia dos Partidos Políticos Brasileiros," In T. Power e C. Zucco (orgs.), O Congresso por Ele Mesmo: Autopercepções da Classe Politica Brasileira. Belo Horizonte, Ed. UFMG, 2011. 